\title{
Assessing the ecological impact of chemical pollution on aquatic ecosystems requires the systematic exploration and evaluation of four lines of evidence
}

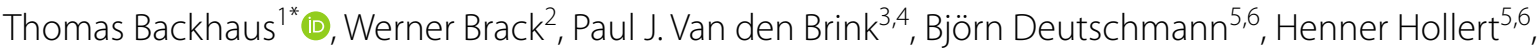 \\ Leo Posthuma ${ }^{7,8}$, Helmut Segner ${ }^{9}$, Thomas-Benjamin Seiler ${ }^{5}$, Ivana Teodorovic ${ }^{10}$ and Andreas Focks ${ }^{3,4}$
}

\begin{abstract}
The aim of the European Water Framework Directive is to ensure good ecological status for all European surface waters. However, although current monitoring strategies aim to identify the presence and magnitude of ecological impacts, they provide little information on the causes of an ecosystem impairment. In fact, approaches to establish causal links between chemical pollution and impacts on the ecological status of exposed aquatic systems are largely lacking or poorly described and established. This is, however, crucial for developing and implementing appropriately targeted water management strategies. In order to identify the role of chemical pollution on the ecological status of an aquatic ecosystem, we suggest to systematically combine four lines of evidence (LOEs) that provide complementary evidence on the presence and potential ecological impact of complex chemical pollution: (1) component-based methods that allow a predictive mixture risk modeling; (2) effect-based methods; (3) in situ tests; (4) field-derived species inventories. These LOEs differ systematically in their specificity for chemical pollution, data demands, resources required and ecological relevance. They complement each other and, in their combination, allow to assess the contribution of chemical pollution pressure to impacts on ecological structure and function. Data from all LOEs are not always available and the information they provide is not necessarily consistent. We therefore propose a systematic, robust and transparent approach to combine the information available for a given study, in order to ensure that consensual conclusions are drawn from a given dataset. This allows to identify critical data gaps and needs for future testing and/or options for targeted and efficient water management.
\end{abstract}

Keywords: Water pollution, Ecological assessment, Mixture toxicity, WFD review, Biological quality elements, Cumulative risks, Weight-of-evidence approaches

\section{Challenge}

The Water Framework Directive (WFD, Directive 2000/60/EC) is the central Directive that guides the assessment and management of European surface waters [1]. It puts the chemical and ecological status of

\footnotetext{
*Correspondence: thomas.backhaus@gu.se

${ }^{1}$ Department of Biological and Environmental Sciences, University

of Gothenburg, Gothenburg, Sweden

Full list of author information is available at the end of the article
}

a waterbody at the center of its status assessments, water quality protection measures and water management. The term "ecological status" is defined in Art. 2 of the Directive as the "quality of the structure and functioning of aquatic ecosystems associated with surface waters", and the normative definitions of the different classes are provided in Annex V of the WFD. Any hazardous chemical or mixtures thereof may act as a factor that limits the likelihood that a good ecological status is maintained or reached. 
One of the professed aims of WFD-based European water management is to achieve at least a "good" ecological status of all European surface waters. Unfortunately, the European Environment Agency concluded in its most recent assessment in 2018 that $60 \%$ of Europe's aquatic ecosystems still fail to achieve this goal [2]. Additional efforts are therefore needed to ensure sustainable water management, in particular the continuous provision of all water-related ecosystem services.

Modeling and risk assessment studies clearly indicate that pollution with complex mixtures of hazardous chemicals impairs the structure and function of aquatic ecosystems in Europe and globally (e.g., [3-5]). The available studies also clearly show that sites and systems differ substantially from each other in terms of chemical pollution and non-chemical stressors [5, 6]. However, it is difficult to confirm the role of chemical mixtures in the ecological impairment of water systems using only the current WFD approaches. Therefore, better strategies are needed to disentangle the site-specific links between chemical pollution and ecological impacts.

According to Annex V of the WFD, ecological status assessments of lakes, rivers, coastal areas and transitional waters are based on the biomonitoring of phytoplankton communities, macroinvertebrates, macrophytes and fish, the so-called biological quality elements (BQEs). These methods, reviewed, e.g., by Birk et al. [7], characterize the presence of ecologically relevant impacts as deviations of the recorded biodiversity from water-type specific reference conditions.

It is a major limitation of current classification methods that they do not allow an assessment of whether the underlying cause of an observed ecosystem impairment is chemical pollution or another (set of) stressor(s). Consequently, the ecological relevance of the pollution measured or modeled to occur at a given site often remains unresolved. This impairs targeted water management because other potential causes of ecosystem impairment, such as changes in hydromorphology, excessive water abstraction, water scarcity, eutrophication or the introduction of neobiota, are usually also present and can overlay or interact with chemical pollution.

No single perfect method can assess ecological impacts and identify the role of chemical pollution at the same time. The complexity of the issue at hand is just too big: Given the huge number of hazardous chemicals present, their fundamentally different modes of action, environmental fate and the resulting site-specific ripple effects through aquatic foodwebs require a suite of complementary approaches that operate along a gradient of biological complexity, ecological realism and chemical specificity.
Water managers and decision-makers work under conditions of substantial resource constraints. Efforts to safeguard or improve water quality therefore need to be well targeted towards the actual cause(s) of an ecosystem impairment [8]. From such a solution-oriented perspective it is insufficient to assess the ecological status of an ecosystem solely by establishing inventories of selected species groups, as requested in Annex V of the WFD. Additional data that provide information on pollution-specific impacts are required that need to be systematically evaluated in the context of information on biodiversity. In the following, we discuss a systematic approach to overcome these limitations, centering around a package of four systematically evaluated lines of evidence (LOE).

\section{Recommendations}

\section{Ensure adequate attention to the problem formulation phase}

The assessment of aquatic ecosystems has different, sometimes even conflicting, aims, and might have different temporal (prospective or retrospective) and spatial (local, regional, continental) perspectives. Adequate attention to the problem formulation of the study is therefore required, in order to identify conceptual approaches and data demands in relation to the available resources and anticipated outcomes. The DPSIR-approach (Driving forces, Pressures, States, Impacts and Responses), which starts with an analysis of the economic activity in an area, provides a framework for such a systematic exploration of possible or even likely outcomes [9].

A study might focus strictly on the status classification according to Annex V of the WFD and/or the identification of pressures and impacts according to Annex II of the WFD (see also [10]). However, in order to provide insights into the ecological consequences of chemical pollution and in order to provide tangible, solution-oriented recommendations for water managers, the following study aims should also be considered, and the study setup adjusted accordingly:

1. Determination of which combination of all the potential impact types (presence of chemicals, changes in hydromorphology, eutrophication, presence of neobiota, etc.) is likely responsible for an impaired ecological status.

2. Quantification of the ecological impact of chemical pollution, in relation to other stressors.

3. Identification of mixture risk drivers.

4. Identification of the BQEs that are particularly vulnerable to the chemical mixtures identified at a site.

5. Identification of risk mitigation options. 
6. Definition of clean-up goals and assessment of remediation success.

7. Impact assessment of pollution sources.

8. Assessment of the ecological consequences of future pollution scenarios.

9. Setting of environmental quality standards for chemical mixtures.

10. Validation of mixture toxicity assessment and prediction models.

The results of the problem formulation stage should be used to define minimum data requirements and essential data blocks before empirical data are generated and evaluated. Depending on the specific study question, the relative importance of the individual LOEs might be quite different. A systematic a priori analysis and assessment of the LOE decision matrix (see below) helps to identify critical LOEs for the study question at hand.

\section{Base the assessment of the ecological consequences} of chemical pollution on a systematic combination of four complementary lines of evidence

We suggest basing the assessment of the ecological impacts of chemical pollution on the following four lines of evidence (LOEs, Fig. 1):

1. Component-based methods (CBMs),

2. Effect-based methods (EBM),

3. In situ methods,

4. Field-derived species inventories.
Not all LOEs will always be available or will always be needed. They should be selected in view of existing knowledge, the available resources and the specific study question [11].

CBMs are discussed in detail in an accompanying policy brief [12]. They comprise a group of widely used, closely related methods that predict the risk of a complex chemical mixture on the basis of knowledge on exposure to and (eco)toxicity of individual chemicals. As such, CBMs are highly specific for chemical stress, often do not require additional experimental data and allow a reliable estimation of the magnitude of mixture risks. CBMs have been used to assess the impact of chemical pollution on each of the BQEs $[12,13]$. At the same time, CBMs consider only those chemicals that are either proven to co-occur at a site from chemical-analytical surveys [14] or that are predicted to co-occur on the basis of modeling studies [5]. CBMs also ignore the ecological context under which an exposure takes place. Finally, CBMs often ignore the potential presence of chemical, toxico-kinetic and -dynamic interactions between the components of a mixture.

EBMs are also presented in a separate policy brief [8]. They provide an ecotoxicological fingerprint of an (often pre-concentrated) water sample from a site, which is generated in a test battery that combines bioassays with apical endpoints and various mode-of-action specific tests. Subsequent chemical fractionation steps and successive testing of more and more simplified fractions of the original sample can provide further information on the (groups of) chemicals that act as "risk drivers" at a site (see also [8]). EBMs thus overcome one of the major

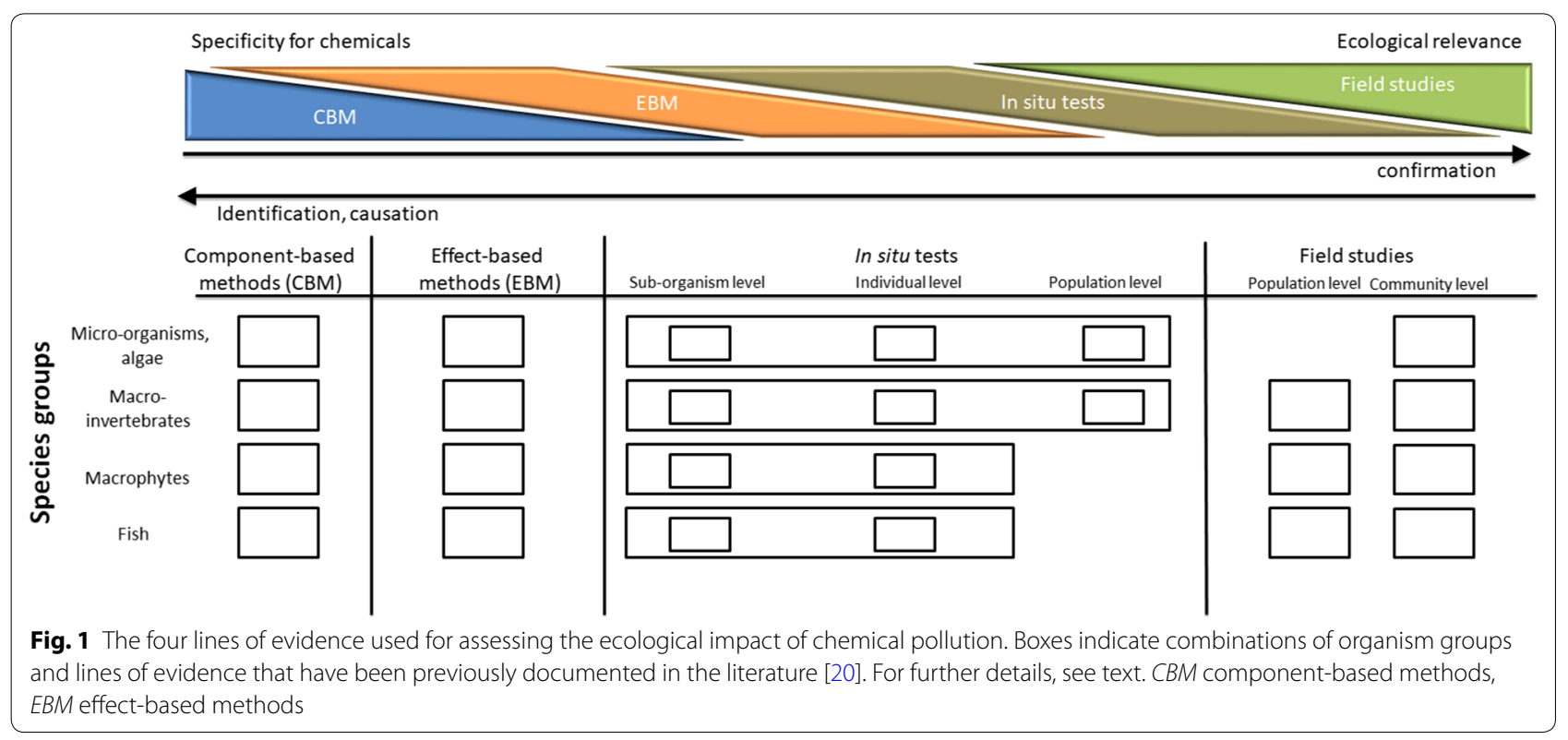


limitations of CBMs, i.e., the exclusive consideration of a set of pre-defined chemicals. They can be combined with effect-based trigger values for delineating water quality classes. Compared to CBMs, EBMs are more resource demanding, as they are based on the ecotoxicological evaluation of a series of site-specific samples using a dedicated test battery. A consensus EBM battery was recently suggested to the European Commission, comprising a selection of small-scale apical assays using algae, zebrafish embryos and daphnids in addition to assays querying mechanism-specific endpoints such as endocrine disruption and reactive toxicity in in vitro assays [8]. However, it should be kept in mind that EBM-derived results will always reflect only the endpoints and particular sensitivities of the assays and organisms included in the test battery. Typically, EBMs use well-known standard test species, so their results do not directly reflect ecotoxicological impacts on the specific biota occurring at a given site, nor their specific ecological interactions.

In situ methods, the third LOE, measures the integrated biological response of individuals that are exposed at a site to the specific complex chemical mixture present. Examples of in situ methods include monitoring of fish caught in the field [15], caging experiments with fish [16] or invertebrates [17], studies on leaf-litter breakdown [18] or tolerance studies with natural microbial communities [19]. Responses measured may be highly integrative if apical endpoints such as survival, reproduction, growth or physiological condition are recorded. They may also be mode-of-action specific, if for example biomarkers or OMIC studies that focus on a selected biochemical pathway are employed. In situ methods reflect not only the impact of the chemical pollution at a site, but also the integrated response of all stressors that are present, which usually include a whole suite of nonchemical stressors such as hydromorphology, temperature, eutrophication, neobiota, etc.

Consequently, many in situ methods are far less specific to chemical pollution than CBMs and EBMs but, for the same reason, provide a more realistic estimate of the total site-specific stress that exposed biota experiences. On the other hand, the aforementioned EBM methods actually allow to pinpoint the potential impact of chemical pollution, as non-chemical stressors are inherently ignored when pre-concentrated water samples are tested in a controlled laboratory environment. In contrast to in situ methods, EBMs also allow to analyze different concentrations and to implement effect-directed fractionation techniques in order to identify mixture toxicity drivers, i.e., those compounds that contribute most to the total toxicity of a mixture [8]. Both, EBMs and in situ approaches are bioassay-based, but the latter require even more resources, as the experimental techniques and/or logistics are usually quite demanding. In situ methods ensure high ecological relevance and are therefore an important component of comprehensive weightof-evidence (WOE) approaches to chemical impact diagnosis [11]. A more detailed overview and examples of typical in situ methods are provided in Backhaus et al. [20].

LOE 4, field-derived species inventories, is the basis of the ecological status assessment under the WFD. A previous overview of the resulting biodiversity indices used by the EU member states for assessing fish, invertebrate, macrophyte and phytoplankton communities is provided by Birk et al. [7]. Annex I of the corresponding Commission Decision (EC 2013) lists the results of the European intercalibration exercise and provides the values of the various indices that define the boundary between high and good ecological status as well as the boundary between good and moderate status.

Species inventories directly reflect the local biodiversity and site-specific ecology, but do not allow to assess causal links to chemical pollution on their own. In fact, the paper by Birk et al. [7] shows that the majority of the biological methods used in the context of the WFD were developed to describe other types of stressors: only four of the 300 methods that are used on a European scale to assess ecological status have been reported to respond to chemical pollution. As a consequence, it cannot be concluded from species inventories alone whether the surveyed organisms are stressed by chemical pollution. For this, it is crucial to assess in the context of more chemical-specific data from LOE1 to LOE3.

\section{Systematically evaluate the empirical and modeling data from all four lines of evidence. Identify data gaps and draw conclusions for risk management}

The results from the four LOEs are integrated according to the strategy outlined in Fig. 1, separately for each species group (phytoplankton, invertebrates, higher plants, fish). In line with the strategy implemented under the Water Framework Directive, the overall ecological conditions at a site should be characterized based on the most sensitive group of species, following the "one out, all out" strategy. However, this strategy should be critically reflected in view of the specific study aim (see above). If the study aims to describe and quantify the ecological impacts of chemical pollution, or if it strives to identify drivers of mixture risk, it is key to focus attention not only on the final status classification, but also consider the reaction of the different BQEs (see e.g., [21, 22]).

The four LOEs define a gradient of increasing ecological relevance and a reciprocal gradient of specificity for chemical pollution (see Fig. 1). CBMs (LOE 1) specifically target chemical pollution and therefore 
allow the ranking of sites and chemicals, but their ecological relevance is limited as neither autecological nor synecological interactions are considered. At the other extreme, field-derived species inventories (LOE 4) provide a snapshot of the site-specific ecological status, but do not provide any evidence on the role of chemical pollution unless combined with other LOEs, see e.g., Chapman and Hollert [11], Rico et al. [23]. LOEs 2 and 3 take interim positions, which might make them particularly suitable to bridge between LOE 1 and LOE 4. In the end, the optimum combination of the four LOEs depends on the specific aim of the study and needs to be carefully optimized case-by-case by the experts involved in the problem formulation phase (see above).

In a perfect world, data from all four LOEs are at hand, and the produced data complement and support each other, so that the assessor can draw clear conclusion on whether and which chemicals impact the ecology of a site. However, in most real-world cases an assessor will struggle with incomplete data and apparently conflicting results. Given the complex and widely divergent data situations that an assessor will have to handle, no strict numerical recipes can be provided for the final integration of LOEs 1-4. Instead we suggest to systematically evaluate the complete decision matrix for the four LOEs [20] for every BQE. That is, we recommend that an assessor should work through the 16 possible combinations of positive/negative findings of the four LOEs for all BQEs included in a given study. Such a systematic evaluation will maximize transparency and identify critical data gaps. This work should commence in the following steps:

1. Identify, compile, document and quality assess the available data.

2. Define the borders between the status classes for each $\mathrm{BQE}$.

3. Compute LOE matrices and interpret results.

In the end, an assessment in the context of the WFD is not only a scientific evaluation, but also the basis for deriving water management plans and legislation. More empirical examples and conceptual work are therefore needed in order to agree on a clear and justiciable strategy especially on how to differentiate between a "good" ecological status (in the legal sense of the WFD) and an impaired ecological status. This is particularly important because this distinction might trigger extensive risk management and mitigation measures. Currently, such a clear distinction is only available for LOE4, i.e., the species inventories according to Annex $\mathrm{V}$ of the WFD, but not for LOEs $1-3$.

\section{Ensure transparent study documentation and data reusability}

It should be emphasized that the whole data analysis pipeline, from recording the raw data at the sites of interest to the final assessment, involves a series of data reduction steps. This always includes an element of subjectivity and expert knowledge, which is why it is important to keep the whole process transparent and retraceable. In particular, all the resulting reports and scientific papers should be made available to the public, by deposition in dedicated open repositories and/or the publication as open-access scientific papers.

Given the complex evaluation and the fact that the assessment will in most cases be depending on expert knowledge, it is also crucial that all underlying raw data (exposure estimates as well as experimental results from all four LOEs) are available for independent scrutiny and for follow-up studies. As a minimum, all data tables should be provided in a native format (Excel tables, CSV tables, SQL databases, etc.) as supporting information in reports and scientific papers. However, the deposition of all data in documented, numeric form in public repositories is preferable; see the discussion in, e.g., Bechhofer et al. [24]. The "Registry of Research Data Repositories" at http://www.re3data.org/ provides an extensive list of the available scientific repositories. We specifically recommend to consider data sharing through the European Open Science Cloud (EOSC; https://www.eosc-porta l.eu).

Also the data-analysis pipeline (the specific process of analyzing the raw data) warrants specific documentation. Highly condensed "Materials and methods" sections in scientific papers and the sprinkling of formulae over a collection of excel sheets are insufficient. Instead, in the spirit of "reproducible research" (e.g., [25]), a combination of data-bases and documented data-analysis pipelines, e.g., in R, python, SAS or similar languages, is recommended.

Finally, all scientific papers that provide input to the diagnostic assessment of European surface waters should be published as open access papers. At the very least, preprints of the final manuscript should be made openly available.

\section{Extend the inventory of biological quality elements used in the WFD ecological status assessment by including micro-organisms}

Figure 1 indicates the biological quality elements (species groups) that are currently used for the ecological status assessment under the WFD, i.e., phytoplankton, invertebrates, higher plants and fish. This overview highlights one particular gap: micro-organisms, especially fungi 
and bacteria, are currently insufficiently considered, although these organisms provide fundamental ecosystem functions such as the recycling of organic matter. We therefore suggest to expand from the WFD's sole focus on micro-algae (diatoms) and also include bacteria and fungi in the ecological status assessment. This should also include an assessment of the possible indirect effects on human health via environmental reservoirs of antimicrobial resistance genes and human pathogens.

\section{Requirements}

The outlined approach (Fig. 1) provides a systematic framework for achieving transparent and therefore hopefully consensual conclusions on whether chemical pollution is the likely pressure responsible for ecological impairments observed at a given site. However, it does not reduce the data demands of the assessment per se. Solid ecological assessments as well as the solution-oriented development of management options will, especially in the view of complex chemical pollution patterns, always depend on sound, well-documented empirical data of high quality.

It might be possible that no final conclusions on the question whether chemical pollution actually causes ecological impacts can be drawn from less-than-perfect data situations. This can be caused by data limitations as well as conflicting results. Such a data situation would occur for example if CBMs (LOE1) and EBMs (LOE2) indicate a risk which is not confirmed by field monitoring data (LOE 4). Such an apparent conflict can be caused by different sensitivities (detection levels) of the methods used and/or different BQEs considered in the different LOEs, amongst other things.

Appropriate attention to the problem formulation phase of the assessment and the development of a fitfor-purpose study plan should minimize the risk of such an outcome (see above). However, despite the inherently solution-oriented nature of the presented framework, sometimes the conclusion that no definitive conclusions can be drawn has to be accepted. Overextending the available data will not provide recommendations that are productive for safeguarding ecosystem quality in the long run. However, an adequately designed study should always result, at the very least, in an identification of the crucial data gaps and therefore pave the way for productive follow-up studies.

Currently, only few studies are available that aimed at identifying the ecological consequence of chemical pollution in a WFD context. All the more important will it be to learn from the existing experiences. It is therefore important to ensure that all ecological, ecotoxicological and chemical-analytical data are made available for scrutiny, are systematically curated and quality assessed, and are finally stored in an online repository that is available long-term. Unfortunately, none of the currently available data collections fulfills these demands completely, and individual study reports provide only a fragmented picture and do not always provide sufficient details. This situation risks that valuable data disappear in the drawers of various research groups, projects and local authorities. These will be lost for broad-scale status classifications, associated diagnostic assessments and eventually trend analyses encompassing evidence on the improvement of water quality after measures are taken.

The various databases developed by, for example, the NORMAN network [26, 27], the WISE system hosted by the EEA [28] and the IPCHEM database that is hosted by the European Joint Research Centre [29] are all promising steps into the right direction, but currently do not include data from all LOEs and sometimes even lack the raw data, so that integrating assessments are still not possible. All these initiatives therefore warrant continuous development and completion, which will depend on dedicated support by the EU Commission and the individual member states.

\section{Achievements}

The outlined approach (Fig. 1) for the detection and quantification of the ecological impact of chemicals uses a statistically supported, transparent and formalized weight-of-evidence (WOE) approach that integrates the four main LOEs: (1) component-based methods (CBMs); (ii) effect-based methods (EBMs); (iii) in situ tests, and (iv) field-derived species inventories. The main idea of the approach is to systematically integrate these four LOEs, so that their strengths complement each other and allow a transparent site-specific assessment with particular attention to establishing links between chemical exposure and ecological impacts, the identification of data gaps and, consequently, the most suitable management options.

The resulting toolbox was applied and optimized in a series of case studies within the collaborative project SOLUTIONS, in the Danube, tributaries to the river Rhine and the river Holtemme in Germany [20].

\section{Danube case study}

Data on the different biological quality elements and fish samples were gathered as part of the Third Joint Danube Survey (JDS3), a large river expedition organized by the International Commission for the Protection of the Danube River (ICPDR) and carried out in 2013 in cooperation with a large number of international scientific institutions [30]. These efforts resulted 
in a rich dataset, including in-depth chemical analyses of water samples, ecotoxicological information from a suite of in vitro bioassays run with extracts from highvolume surface water samples and passive samplers [31, 32], data from a battery of in situ biomarkers in sentinel fish (Alburnus alburnus and Neogobius sp., see [15]), as well as fish and macroinvertebrate community data [23, 30].

The toolbox approach as outlined above was applied to the JDS3 data [20], and a systematic evaluation of the empirical data was performed. The principal aim was to assess the likelihood of chemical impacts on the ecological conditions at the sampling sites. Following the systematic approach, the multitude of data was transformed in a transparent way into comprehensible matrices for a subset of the sampling sites (e.g., Fig. 2). Sites showed different consistency of responses across the LOEs. For example for fish, 3 sites showed a consistent impairment of all LOEs, from predictive toxicity modeling over biomarker responses up to communitylevel indicators, indicating high likelihood of chemical

\begin{tabular}{|c|c|c|c|c|c|}
\hline \multicolumn{6}{|c|}{ Weight of evidence } \\
\hline & \multicolumn{3}{|c|}{ Fish } & \multicolumn{2}{|c|}{ Invertebrates } \\
\hline & LOE1 & LOE3 & LOE4 & LOE1 & LOE4 \\
\hline JDS50 & 2 & 2 & & 2 & 1 \\
\hline JDS54 & 2 & 2 & & & \\
\hline JDS38 & 2 & 2 & 2 & 2 & 2 \\
\hline JDS48 & 2 & 2 & 2 & & \\
\hline JDS53 & 2 & 2 & 2 & 2 & 2 \\
\hline JDS40 & 2 & 2 & 1 & 2 & 2 \\
\hline JDS62 & 2 & 2 & 1 & 2 & 2 \\
\hline JDS66 & 2 & 2 & 1 & 2 & 2 \\
\hline JDS67 & 2 & 2 & 1 & 2 & 1 \\
\hline JDS58 & 2 & 1 & & & \\
\hline JDS39 & 2 & 1 & 2 & 2 & 1 \\
\hline JDS47 & 2 & 1 & 2 & 2 & 2 \\
\hline JDS60 & 2 & 1 & 2 & 2 & 1 \\
\hline JDS27 & 2 & 1 & 1 & 2 & 2 \\
\hline JDS28 & 2 & 1 & 1 & 2 & 2 \\
\hline JDS31 & 2 & 1 & 1 & 2 & 2 \\
\hline JDS33 & 2 & 1 & 1 & 2 & 2 \\
\hline JDS36 & 2 & 1 & 1 & 2 & 2 \\
\hline JDS65 & 2 & 1 & 1 & 2 & 2 \\
\hline
\end{tabular}

Fig. 2 Weight of evidence matrices for 19 sampling sites of the Danube case study, identifiers in the left column. Values indicate 2: CLEAR—clear signal, 1: MID—moderate signal, 0: NO—no signal. Empty boxes indicate missing values. For the derivation of the LOE values see [20] impacts. However, while for all of the analyzed sites, toxic pressure (LOE1) suggested chemicals as the main potential cause, this was confirmed by biomarker responses (LOE3) for only about $50 \%$ of the analyzed sites.

Despite its sheer size and attention to detail, the Danube case study faced several technical challenges, in particular related to the non-availability of ecotoxicity data for most of the detected chemicals, which hampered a consistent evaluation of LOE1 [23]. Also, missing reference values for biomarkers derived from local fish species, and for community indices proved to be a bottleneck for the evaluation of the recorded data (LOE3 and LOE4).

Data recorded at the different JDS3 sampling sites were heterogeneous, which limited the broad-scale assessment of pollution impacts along the Danube River. For only 19 of 58 sampling sites data for at least three 3 LOEs were recorded. In particular, data for LOE2 data were missing for most sites. However, the results indicate that a number of sites with moderate signals in LOE3 and 4 should be queried in a future survey with an extended battery of biomarker tests (LOE2), including assays for endocrine disruption and mutagenicity. All of this emphasizes the critical importance of the problem formulation step. Even such massive, seemingly all-encompassing largescale monitoring activities such as the JDS3, might need to consider more systematically the trade-offs between the different possible aims of such a study (see above).

If the primary aim would be to determine which combination of all the potential impact types is likely responsible for an impaired ecological status (aim 1 in the list presented above), a more complete set of data that systematically covers all LOEs collected perhaps at a smaller number of sampling sites might have maximized the chance of drawing firmer conclusions. However, if, on the other hand, the primary aim would be the identification and impact assessment of pollution sources (aim 7), monitoring sites might have better been consistently positioned following an upstream-downstream approach. Such a strategy was recently successfully implemented in a dedicated study near in the Danube near Novi Sad [33].

\section{Rhine case study}

A second case study focused on the in situ impacts of chemical pollution on microbial communities up- and downstream of upgraded and non-upgraded wastewater plants $[19,20]$. The authors specifically investigated microbial communities (photoautotrophic biofilms) because they are ecologically complex and allow to identify pollution-driven ecological impacts such as pollution-driven succession. They are also crucial ecosystem components, driving a range of ecosystem services and form the basis of aquatic food webs. 
Using in situ tests with microbial communities (LOE3), the authors observed clear relationships between micropollutant levels, shifts in community structure, and subsequent pollution-induced tolerance development (PICT). A decrease of chemical pollution, as a result of upgrading the wastewater treatment at one of the sampling sites with activated carbon filtration, led to a loss of community tolerance and to a structural recovery. The study thus did not only demonstrate the suitability of using PICT for the risk assessment of micropollutants in ecological settings, and to assess community recovery. It also demonstrates the positive impacts that STP upgrades have on the ecology downstream of the wastewater entry point.

These results were combined with CBMs (LOE 1) in order to identify the drivers of mixture risks, which turned out to be photosynthesis inhibiting biocides. Subsequent laboratory studies confirmed this assessment. The combination of LOE1 and LOE3 therefore did not only allow an assessment of the ecological status of wastewater-impacted streams and confirmed the success of risk mitigation measures, but it also enabled the identification of the causative chemicals.

\section{Acknowledgements}

Not applicable.

\section{Authors' contributions}

TB and AF drafted the manuscript. All co-authors helped to refine it and agreed on the final version. All authors read and approved the final manuscript.

\section{Funding}

Open access funding provided by University of Gothenburg. The research leading to this Policy Brief was part of the SOLUTIONS project which received funding from the European Union Seventh Framework Programme (FP7ENV-2013) under Grant Agreement No 603437.

\section{Availability of data and materials}

Not applicable.

\section{Ethics approval and consent to participate} Not applicable.

\section{Consent for publication}

Not applicable.

\section{Competing interests}

The authors declare that they have no competing interests.

\footnotetext{
Author details

1 Department of Biological and Environmental Sciences, University of Gothenburg, Gothenburg, Sweden. ${ }^{2}$ Department of Effect-Directed Analysis, Helmholtz Centre for Environmental Research UFZ, Leipzig, Germany. ${ }^{3}$ Wageningen Environmental Research, Wageningen, The Netherlands. ${ }^{4}$ Aquatic Ecology and Water Quality Management Group, Wageningen University, Wageningen, The Netherlands. ${ }^{5}$ Department of Ecosystem Analysis, Institute for Environmental Research, Aachen University, Aachen, Germany. ${ }^{6}$ Department Evolutionary Ecology and Environmental Toxicology, Faculty Biological Sciences, Goethe University Frankfurt, Frankfurt, Germany. ${ }^{7}$ Centre for Sustainability, Environment and Health, National Institute for Public Health and Environment RIVM, Bilthoven, The Netherlands. ${ }^{8}$ Department of Environmental Science, Radboud University, Nijmegen, The Netherlands. ${ }^{9}$ Centre for Fish and Wildlife
}

Health, University of Bern, Bern, Switzerland. ${ }^{10}$ University of Novi Sad, Faculty of Sciences, Novi Sad, Serbia.

Received: 18 August 2019 Accepted: 5 December 2019

Published online: 26 December 2019

\section{References}

1. European Parliament and Council (2000) Directive 2000/60/EC of the European Parliament and of the Council of 23 October 2000 establishing a framework for Community action in the field of water policy. Off J Eur Communities L 327:1-72

2. European Environment Agency (EEA) (2018). European waters-Assessment of status and pressures, EEA Report No 7/2018

3. Malaj E, Peter C, Grote M, Kühne R, Mondy CP, Usseglio-Polatera P, Brack W, Schäfer RB (2014) Organic chemicals jeopardize the health of freshwater ecosystems on the continental scale. Proc Natl Acad Sci 111(26):9549-9554

4. Posthuma L, Brack W, van Gils J, Focks A, Müller C, de Zwart D, Birk S (2019) Mixtures of chemicals are important drivers of impacts on ecological status in European surface waters. Environ Sci Eur 31(1):71

5. Van Gils J et al (2019) The European Collaborative Project SOLUTIONS developed models to provide diagnostic and prognostic capacity and fill data gaps for chemicals of emerging concern. Environ Sci Eur 31:72

6. Grizzetti B, Pistocchi A, Liquete C, Udias A, Bouraoui F, van de Bund W (2017) Human pressures and ecological status of European rivers. Scientific Rep 7(1):205

7. Birk S, Bonne W, Borja A, Brucet S, Courrat A, Poikane S, Solimini A, van de Bund W, Zampoukas N, Hering D (2012) Three hundred ways to assess Europe's surface waters: an almost complete overview of biological methods to implement the Water Framework Directive. Ecol Ind 18:31-41

8. Brack W, Aissa SA, Backhaus T, Dulio V, Escher BI, Faust M, Hilscherova K, Hollender J, Hollert H, Müller C, Munthe J (2019) Effect-based methods are key. The European Collaborative Project SOLUTIONS recommends integrating effect-based methods for diagnosis and monitoring of water quality. Environ Sci Eur 31(1):10

9. Posthuma L, Munthe J, van Gils J, Altenburger R, Müller C, Slobodnik J, Brack W (2019) A holistic approach is key to protect water quality and monitor, assess and manage chemical pollution of European surface waters. Environ Sci Eur 31(1):67

10. European Commission (2003) Common implementation strategy for the water framework directive (2000/60/EC): guidance document No 3: Analysis of Pressures and Impacts

11. Chapman PM, Hollert H (2006) Should the sediment quality triad become a tetrad, a pentad, or possibly even a hexad? J Soils Sediments 6(1):4-8

12. Posthuma L, Altenburger R, Backhaus T, Kortenkamp A, Müller C, Focks A, de Zwart D, Brack W (2019) Improved component-based methods are key to characterize the risk of complex chemical pollution in surface waters. Environ Sci Eur 31:70

13. Kortenkamp A et al (2019) Mixture risks threaten water quality: the European Collaborative Project SOLUTIONS recommends changes to the WFD and better coordination across all pieces of European chemicals legislation to improve protection from exposure of the aquatic environment to multiple pollutants. Environ Sci Eur 31:69

14. BrackW, Hollender J, de Alda LM, Müller C, Schulze T, Schymanski E (2019) High-resolution mass spectrometry to complement monitoring and track emerging chemicals and pollution trends in European water resources. Environ Sci Eur 31:62

15. Deutschmann B, Kolarevic S, Brack W, Kaisarevic S, Kostic J, KracunKolarevic M, Liska I, Paunovic M, Seiler TB, Shao Y, Sipos S, Slobodnik J, Teodorovic I, Vukovic-Gacic B, Hollert H (2016) Longitudinal profiles of the genotoxic potential of the River Danube on erythrocytes of wild fish assessed using the comet and micronucleus assay. Sci Total Environ 573:1441-1449

16. Oikari A (2006) Caging techniques for field exposures of fish to chemical contaminants. Aquat Toxicol 78(4):370-381

17. Besse JP, Geffard O, Coquery M (2012) Relevance and applicability of active biomonitoring in continental waters under the Water Framework Directive. TrAC Trends Anal Chem 36:113-127 
18. Zubrod JP, Feckler A, Englert D, Koksharova N, Rosenfeldt RR, Seitz F, Schulz R, Bundschuh M (2015) Inorganic fungicides as routinely applied in organic and conventional agriculture can increase palatability but reduce microbial decomposition of leaf litter. J Appl Ecol 52(2):310-322

19. Tlili A, Corcoll N, Arrhenius Å, Backhaus T, Hollender J, Creusot N, Wagner B, Behra R (2019) Tolerance patterns in stream biofilms link complex chemical pollution to ecological impacts. Environ Sci Technol. Accepted for publication

20. Backhaus T, Segner H, Hollert H, Deutschmann B, van den Brink PJ, Seiler TB, Teodorovic I, Focks A (2018) Diagnostic toolbox for ecological effects of pollutant mixtures, including bio-tests, trait-based database and detection tool and WoE studies at hot-spot sites. External Deliverable of the SOLUTIONS project. https://www.solutions-project.eu/results-products/

21. Gustavsson M, Kreuger J, Bundschuh M, Backhaus T (2017) Pesticide mixtures in the Swedish streams: environmental risks, contributions of individual compounds and consequences of single-substance oriented risk mitigation. Sci Total Environ 598:973-983

22. Nowell LH, Moran PW, Schmidt TS, Norman JE, Nakagaki N, Shoda ME, Mahler BJ, Van Metre PC, Stone WW, Sandstrom MW, Hladik M (2018) Complex mixtures of dissolved pesticides show potential aquatic toxicity in a synoptic study of Midwestern US streams. Sci Total Environ 613:1469-1488

23. Rico A, van den Brink PJ, Leitner P, GrafW, Focks A (2016) Relative influence of chemical and non-chemical stressors on invertebrate communities: a case study in the Danube River. Sci Total Environ 571:1370-1382

24. Bechhofer S, Buchan I, De Roure D, Missier P, Ainsworth J, Bhagat J, PhilipCouch Cruickshank D, Delderfield M, Dunlop I, Gamble M, Michaelides D, Owen S, Newman D, Sufi S, Goble C (2013) Why linked data is not enough for scientists. Fut Gener Comput Syst 29(2):599-611

25. Mesirov JP (2010) Accessible reproducible research. Science 327(5964):415-416

26. Dulio V, Van Bavel B, Brorström-Lundén E, Harmsen J, Hollender J, Schlabach M, Slobodnik J, Thomas K, Koschorreck J (2018) Emerging pollutants in the EU: 10 years of NORMAN in support of environmental policies and regulations. Environ Sci Eur 30(1):5
27. Norman Network Databases (2019) https://www.norman-netwo rk.net/?q=node/24. Accessed Feb 2019

28. European Environment Agency (EEA) (2019). WISE-Water Information System for Europe. https://water.europa.eu/. Accessed Feb 2019

29. Joint Research Centre (JRC) (2019). Information Platform for Chemical Monitoring (IPCHEM). https://ipchem.jrc.ec.europa.eu/RDSIdiscovery/ ipchem/index.html. Accessed Feb 2019

30. Liška I, Wagner F, Sengl M, Deutsch K, Slobodník J (2015) Joint Danube Survey 3-a comprehensive analysis of danube water quality, final scientific report. International Commission for the Protection of the Danube River, Vienna. ISBN 978-3-200-03795-3

31. Neale PA, Ait-Aissa S, Brack W, Creusot N, Denison MS, Deutschmann B, Hilscherova K, Hollert H, Krauss M, Novaak J, Schulze T, Seiler TB, Serra $\mathrm{H}$, Shao Y, Escher BI (2015) Linking in vitro effects and detected organic micropollutants in surface water using mixture-toxicity modeling. Environ Sci Technol 49:14614-14624

32. Schulze T, Krauss M, Novak J, Hilscherova K, Ait-Aissa S, Creusot N, Macova M, Neale P, Escher BI, Gomes T, Tollefsen KE, Tarcai Z, Shao Y, Deutschmann B, Seiler TB, Hollert H, Tarabek P, Tousova Z, Slobodnik J, Walz KH, Brack W (2015) Large volume sampling and effect-based screening. In: Liška I, Wagner F, Sengl M, Deutsch K, Slobodník J (eds) Joint Danube Survey 3, Final Scientific Report. International Commission for the Protection of the Danube River, Vienna, pp 284-295

33. Hashmi MAK, Escher BI, Krauss M, Teodorovic I, Brack W (2018) Effectdirected analysis (EDA) of Danube River water sample receiving untreated municipal wastewater from Novi Sad, Serbia. Sci Total Environ 624:1072-1081

\section{Publisher's Note}

Springer Nature remains neutral with regard to jurisdictional claims in published maps and institutional affiliations.

\section{Submit your manuscript to a SpringerOpen ${ }^{\circ}$ journal and benefit from:}

- Convenient online submission

- Rigorous peer review

- Open access: articles freely available online

- High visibility within the field

- Retaining the copyright to your article

Submit your next manuscript at $\boldsymbol{\nabla}$ springeropen.com 